\title{
Erratum to: Methods of Intellectual Analysis in Medical Diagnostic Tasks Using Smart Feature Selection (Volume 28, Issue 4, page 637) ${ }^{1}$
}

\author{
N. Yu. Ilyasova ${ }^{a, b, *}$, A. S. Shirokanev ${ }^{a, b}$, A. V. Kupriyanov ${ }^{a, b}$, \\ R. A. Paringer ${ }^{a, b}$, D. V. Kirsh ${ }^{a, b}$, and V. A. Soifer ${ }^{a, b}$ \\ aIPSI RAS - Branch of the FSRC "Crystallography and Photonics" RAS, Samara, Russia \\ ${ }^{b}$ Samara National Research University, Samara, Russia \\ *e-mail: ilyasova.nata@gmail.com
}

DOI: $10.1134 / \mathrm{S} 1054661819010231$

The author's name R. A. Paringev should read $R$. A. Paringer

The author's name A. V. Soifer should read V. A. Soifer

The original article can be found online at

https://doi.org/10.1134/S1054661818040144

\footnotetext{
${ }^{1}$ The article is published in the original.
}

Received December 21, 2018 